\title{
Effective Ways of Education Modernization Against the Background of Beautiful Rural Construction
}

\author{
Xiaobo Li \\ Jiangsu University \\ Zhenjiang, China
}

\author{
Wanlu Zhang \\ Jiangsu University \\ Zhenjiang, China
}

\author{
Xujian Zhou \\ Yixing Heqiao Experimental Primary School \\ Yixing, China
}

\begin{abstract}
In the process of building a well-off society in an all-round way, the modernization of rural education plays an important role in overall. Without the modernization of rural education, it is difficult to realize the modernization of agriculture and rural areas. Compulsory education is the top priority of education and a basic public undertaking that must be prioritized. The implementation of the rural revitalization strategy puts forward new requirements for the overall improvement of school conditions and quality of education in rural compulsory education. Promoting the integration of urban and rural compulsory education in the county is an inevitable choice for improving the quality of education and promoting education equity in the new era.
\end{abstract}

Keywords-educational education; educational equity

modernization;

compulsory

\section{INTRODUCTION}

The "Implementation of village revitalization strategy" proposed by the party's 19 major reports is a major historical task of establishing a well-off society and building a socialist modernized power comprehensively with the strategy of rejuvenating the nation, the strategy of talent power, the strategy of innovation-driven development, the strategy of regional coordinated development, the strategy of sustainable development and the development of civil-military integration. The report also pointed out that it is necessary to give priority to the development of education and promote the integrated development of urban and rural compulsory education. The implementation of the rural revitalization strategy must attach importance to the revitalization of rural education. The construction of beautiful rural areas needs to promote the integrated development of urban and rural compulsory education and accelerate the modernization of rural education.

\section{PROMOTING THE INTEGRATION OF COMPULSORY EDUCATION IN URBAN AND RURAL AREAS IS THE INEVITABLE CHOICE OF IMPROVING EDUCATION QUALITY AND PROMOTING EDUCATION FAIRNESS IN THE NEW ERA}

Since entering the new century, China's urbanization has accelerated significantly. However, due to the role of the market mechanism, the factor market for urban and rural coordinated development has not been established. The factor flow is still from rural to urban. The imbalance between urban and rural development still exists, and the urban-rural dual structure contradiction has not been fundamentally solved. At present, China has entered the stage of decisive victory in building a well-off society in an all-round way, and is in a critical period of in-depth development of new urbanization. The 19th National Congress of the Communist Party of China put forward the "implementation of rural revitalization strategy". In December 2017, the Central Rural Work Conference was held to study the important policies for implementing the rural revitalization strategy. The meeting noted that "without the modernization of agricultural and rural areas, there would be no modernization of the country." It is necessary to "establish and improve the system and policy system for the integration of urban and rural development in accordance with the general requirements of industrial prosperity, ecological livability, civilized civilization, effective governance, and affluent life, and coordinate the promotion of rural economic construction, political construction, cultural construction, social construction, and ecology, civilization construction and party building".

In the process of building a well-off society, the modernization of rural education plays an important role in overall. Compulsory education is the top priority of education work, is a public welfare undertaking that the state must guarantee, and it is a basic public enterprise that must be prioritized for development. In order to fulfill the requirements of a well-off society and promote the sustainable and healthy development of compulsory education on February 24, 2017, the People's Government of Jiangsu Province issued the "Several Opinions of the 
Provincial Government on Promoting the Integration of Urban and Rural Compulsory Education to Promote the Balanced Development of Quality and Quality", It is required to "improve the quality of education in weak schools" and "encourage the development of schools in the county and across regions to help, manage, and organize schools to share quality education resources". "Educational modernization mainly includes modernization at the conceptual level, modernization at the institutional level, and modernization at the material level (Liu Haimin, 2015)". The integration of urban and rural compulsory education is a favorable measure of rural educational modernization. It is a new institutional mechanism and development model to promote the modernization of rural education under the guidance of the concept of "balanced urban and rural education". It is the inevitable choice for improving the quality of education and promoting education fairness in China's new era.

\section{SCHOOL EDUCATION GROUP OF URBAN AND RURAL COMPULSORY EDUCATION IS AN EFFECTIVE CARRIER TO PROMOTE THE INTEGRATION OF URBAN AND RURAL COMPULSORY EDUCATION IN COUNTY}

In order to carry out some opinions of the provincial government, to promote the co-operation between urban and rural schools, to reduce the quality differences, to achieve a balanced development of compulsory education, all over the useful exploration.

\section{A. Basic Principles for the Establishment of Urban and Rural Compulsory Education Groups}

1) The principle of regional advancement: Strengthen the top-level design and layout of urban and rural group-run schools, and determine the education group with the leading school as the core and other schools as the branch schools, and gradually advance from point to point.

2) The principle of subject excitation: Fully guarantee the main position of managers and teachers in the group in running schools, and stimulate the enthusiasm and creativity of the school's active development. Respecting the value recognition of the leading schools and branches in the school-running philosophy, management methods and cultural development, the principle of "double-selection and administrative co-ordination" is to coordinate the local schools.

3) The principle of institutional innovation: Each urban and rural education Group creatively formulates the group school regulations, optimizes the internal management structure, clarifies the development plan, establishes the collective operation mechanism which takes the common vision as the soul, the system system as the framework, and the rule procedure as the link.

4) Principle of sharing symbiosis: Through the advanced concept of running a school, the construction of a scientific management system, the flexible flow of key teachers, the sharing of educational and teaching resources, the sharing of facilities and equipment, and the symbiosis of school-running culture, Enhance the school's ability to "improve" and "rebuild", gradually form their own advantages, establish the school characteristics, improve the quality of education.

\section{B. The Concrete Mode of Urban and Rural Compulsory Education Group Formation}

Adopting the " $1+\mathrm{N}$ " mode, the leading school will take the lead and choose 1 2 schools as the leading schools. The leading school is the group's main school, plus the " $\times \times$ Education Group" school card, the branch school retains the original school name, and the " $x \times$ Education Group $\times x$ Branch School" school card is added. The legal person of each school does not change, the bureau does not change, the personnel relations are invariable, the person, the wealth, the matter maintains relatively independent. A close relationship between the leading school and the branch school to establish management and intercommunication, teacher exchange, research and training linkage, quality advancement, cultural co-construction, and assessment synchronization. Through the group to give full play to the advantages of the group, the implementation of the management model, the sharing of education resources, and continuously improve the level of schooling and quality of education, to achieve the re-expansion of high-quality resources, school-grade upgrade, and better promote and promote the quality of compulsory education in our city balanced development.

\section{The Focus of the Work of Urban and Rural Compulsory Education Groups}

1) Establishing a decision-making center: The highest decision-making body of the urban and rural education group is the joint meeting of the principals, which is composed of the principal president of the group, the principals of each branch, and the relevant leaders of the education bureau.

2) Clarifying the leadership mechanism: The urban and rural education group implements the principal responsibility system under the leadership of the president.

3) Optimizing the management mode: Establish and unify the management system, promote the overall promotion of culture, brand creation, team building, management innovation, quality improvement, and enlarge the quality education resources.

4) Promoting the teaching management: The schools in the group carry out a synchronized teaching management mode, on the basis of high quality implementation of the national curriculum, gather resources to build a quality course with the characteristics of the group and regional characteristics.

5) Strengthening the allocation of teachers: Establish a library of teacher information resources within the group, find out the structure of teachers in various disciplines and the resources of key teachers, and innovate new mechanisms for teacher training. Sixth, unified assessment of the reward. Formulate urban and rural group-run assessment indicators, 
evaluate the group's education level as a whole, and introduce third-party evaluation agencies to conduct performance evaluation. Seventh, promote the characteristics of development. Vigorously shaping the urban and Rural Education group's cultural brand, in the school-running philosophy, the culture of the formation of the group's characteristics.

\section{IMPLEMENTING SAFEGUARD MEASURES, ATtACHING IMPORTANCE TO SYSTEM CONSTRUCTION, AND STRENGTHENING ASSESSMENT AND EVALUATION ARE THE KEY TO THE EFFECTIVENESS OF EDUCATION GROUPS IN URBAN AND RURAL COMPULSORY EDUCATION SCHOOLS}

The establishment of urban and rural compulsory education group, the realization of high-quality education resources to enlarge and regenerate, promote the group of schools "symbiotic win", so that high-quality urban schools and common rural schools to develop together, is to promote the integration of urban and rural compulsory education, promote the development of high-quality educational balance in the county area of beneficial exploration.

\section{A. Implementation of Safeguard Measures}

1) Strengthening organizational leadership: A leading group for the promotion of urban and rural group education should be established, and an office should be set up under the leading group to give full play to the subjective initiative of each group and to carry out creative work according to its own actual situation.

2) Strengthening Investment protection: In terms of funding support, the Education Bureau actively leaned toward the pilot group and supported the pilot work. Set up special funds to ensure the needs of school leaders and key teachers, the development of high-quality curriculum, the linkage of teaching and research training, and the sharing of venue resources during the process of urban and rural group-run schools. We will take the lead in safeguarding the basic construction of the branch campus and strive to build in the venue. The gap between the installation of facilities and equipment and the improvement of office conditions has narrowed the gap with leading schools.

3) Creating a good atmosphere: Give full play to the role of media, increase publicity efforts, adhere to the typical demonstration, vitalize, the emergence of the urban and rural groups in the "Good school", as well as promote the urban and rural groups to run the experience and effectiveness of timely summary and publicity, guide and mobilize the whole society to pay attention to, care for, support the reform and development of basic education Forming a good atmosphere for the whole society to understand and support the urban and rural group.

\section{B. Emphasis on System Construction}

The primary task of the urban and rural compulsory education school education group is to formulate the group management charter, optimize the internal management structure, clarify the development plan, and study the management system. The Group Management Committee is the highest decision-making body of the Group and is responsible for the overall work of the Education Group.

The head school regularly convene the branch leadership team to participate in group administrative joint meetings, wisdom management seminars, line work training, out-oftown study and other seminars, to help the branch school management to continuously optimize management measures, improve management level, work together, and serve the development of teachers and students wholeheartedly. It ensures that the Education Group adheres to the unified concept, share common wisdom, pursue unity goals, and diversify individuality, so as to achieve the goal of integrating multiculturalism, adhering to the characteristics of running schools, building endeavor teams, and improving school quality.

\section{Strengthened Assessment and Evaluation}

1) Principles of assessment and evaluation: First, adhere to the principle of incremental evaluation. Emphasis on the development of incremental evaluation, from the beginning to see the changes, scientific and objective evaluation of school management and education and teaching work of new, new growth, new development. Second, adhere to the principle of quality and balance. Actively promote the radiation, sinking, integration and complementation of quality education resources within the Education Group, continuously expand coverage and benefits, and promote the balanced development of education quality in the city. Third, adhere to the principle of innovation and development. Based on the foundation of solid foundation, we actively explore the path and method of practicing innovation and development, and strive to achieve continuous optimization of education and teaching concepts and rapid improvement of the level of running schools.

2) Assessment and evaluation content: Management system, teaching staff, environmental resources, teaching activities, quality of running schools, and innovative features.

3) Assessment steps: The method of combining school self-evaluation and city-level comprehensive assessment, takes three years as a cycle, carries out a yearly

4) Application of evaluation results: Implement the evaluation tree first. The evaluation results of each education group are divided into two categories: "excellent" and "qualified". The proportion of "excellent" in principle does not exceed $40 \%$ of the total number of education groups in the city. The results of the examination also serve as the basis for the annual assessment and reward and punishment of the principal and main school of the education group. Then implement the award to supplement. The special fund for the establishment of the Municipal Education Group Management School will be established, and the education group with the evaluation result of 
"excellent" will be honored. Finally, a one-vote veto system was implemented. If there are serious violations of schoolrunning behavior, major safety responsibility accidents, serious violations of discipline and law, serious petition cases, etc. within the group, the evaluation of the education group will be vetoed by one vote.

\section{CONCLUSION}

"The development of rural education to help rural children learn to be successful, to prevent the intergenerational transmission of poverty, is a work in the contemporary, benefit in the future." In the process of implementing village revitalization strategy, as long as the local government, school administrators and teachers work together, through the implementation of management mode, education resources sharing, and continuously improve the level of school and education quality, to achieve the reexpansion of high-quality resources, school grade re-upgrade, better promote and promote the quality of compulsory education in our city balanced development, Thus "to make agriculture an industry with a head start, to make farmers an attractive profession, and to make the countryside a beautiful home for living and working. (Dong Jun and Wang Libin, 2017)"

\section{REFERENCES}

[1] Liu Haimin (2015). Introduction to Education.100-102

[2] Dong Jun and Wang Libin (2017). Central Rural Work Conference held in Beijing. Report of People's Daily. 30 December 2017. 